\title{
The impact of air pollution on COVID-19 pandemic varied within different cities in South America using different models
}

\author{
Haining Huang ${ }^{1} \cdot$ Congtian Lin ${ }^{2,3} \cdot$ Xiaobo Liu ${ }^{1} \cdot$ Liting Zhu ${ }^{1,3} \cdot$ Ricardo David Avellán-Llaguno ${ }^{1,3}$. \\ Mauricio Manuel Llaguno Lazo ${ }^{4}$ Xiaoyan $\mathrm{Ai}^{5}$. Qiansheng Huang ${ }^{1}$ (D)
}

Received: 27 April 2021 / Accepted: 15 July 2021 / Published online: 31 July 2021

(C) The Author(s), under exclusive licence to Springer-Verlag GmbH Germany, part of Springer Nature 2021

\begin{abstract}
There is a rising concern that air pollution plays an important role in the COVID-19 pandemic. However, the results were not consistent on the association between air pollution and the spread of COVID-19. In the study, air pollution data and the confirmed cases of COVID-19 were both gathered from five severe cities across three countries in South America. Daily real-time population regeneration $\left(R_{t}\right)$ was calculated to assess the spread of COVID-19. Two frequently used models, generalized additive models (GAM) and multiple linear regression, were both used to explore the impact of environmental pollutants on the epidemic. Wide ranges of all six air pollutants were detected across the five cities. Spearman's correlation analysis confirmed the positive correlation within six pollutants. Rt value showed a gradual decline in all the five cities. Further analysis showed that the association between air pollution and COVID-19 varied across five cities. According to our research results, even for the same region, varied models gave inconsistent results. For example, in Sao Paulo, both models show $\mathrm{SO}_{2}$ and $\mathrm{O}_{3}$ are significant independent variables, however, the GAM model shows that $\mathrm{PM}_{10}$ has a nonlinear negative correlation with $R_{t}$, while $\mathrm{PM}_{10}$ has no significant correlation in the multiple linear model. Moreover, in the case of multiple regions, currently used models should be selected according to local conditions. Our results indicate that there is a significant relationship between air pollution and COVID-19 infection, which will help states, health practitioners, and policy makers in combating the COVID-19 pandemic in South America.
\end{abstract}

Keywords COVID-19 · Air pollution · Generalized additive model $\cdot$ Multiple linear regression $\cdot$ South America $\cdot$ Daily real-time population regeneration

Haining Huang and Congtian Lin contributed equally to this work.

Responsible Editor: Lotfi Aleya

Xiaoyan Ai

jxsfybjyaxy@sina.com

Qiansheng Huang

qshuang@iue.ac.cn

1 Center for Excellence in Regional Atmospheric Environment, Key Lab of Urban Environment and Health, Institute of Urban Environment, Chinese Academy of Sciences, Xiamen 361021, China

2 Key Laboratory of Animal Ecology and Conservational Biology, Institute of Zoology, Chinese Academy of Sciences, Beijing 100101, PR China

3 University of Chinese Academy of Sciences, Beijing 100049, PR China

4 University of Franca/UNI-FACEF, Franca 14400160, Brazil

5 Jiangxi Provincial Key Laboratory of Birth Defect for Prevention and Control, Jiangxi Provincial Maternal and Child Health Hospital, 318 Bayi Avenue, Nanchang 330006, PR China

\section{Introduction}

In late December 2019, a novel coronavirus, named COVID19, was first reported in Wuhan, Hubei Province, China (Daraei et al. 2020; Lu et al. 2020; Wu et al. 2020). Acute Respiratory Syndrome Corona Virus 2 (SARS-CoV2) (Lu et al. 2020) is the pathogenic agent of COVID-19 and most of the infected had clinical manifestations of fever and shortness of breath (Chen et al. 2020). This epidemic has caused serious demographic changes and unemployment (Bashir et al. 2020b). It has been confirmed COVID-19 can be transmitted through direct contact (human-to-human) (Chan et al. 2020). A total of $20,871,160$ patients with COVID-19 had been confirmed worldwide as of August 13, 2020, and 81 countries have more than 10,000 confirmed cases (https:// www.hopkinsmedicine.org/coronavirus). South America accounts for about $27 \%$ of the world's confirmed cases, making it the region with the highest number of confirmed 
cases. The confirmed cases in South America until August 13, 2020 are shown in Fig. 1.

Air pollution remains a major public health threat globally (Hashim et al. 2021). Previous results indicated that air pollution can increase the spread of diseases (Bell et al. 2004; Goings et al. 1989; Wei et al. 2019). Previous studies showed that droplets with virus can stay suspended in the air for a short time, and these particles may pose a threat of infection if they are inhaled by nearby persons. This approach makes it possible for people infected with COVID-19 to facilitate the spread of infection (Anfinrud et al. 2020; Meselson 2020). Lab experiments have demonstrated that the SARS-CoV-2 virus can survive in aerosols for days or weeks, making the virus susceptible to airborne contamination (Liu et al. 2020). Particulate matters such as $\mathrm{PM}_{10}$ and $\mathrm{PM}_{2.5}$, due to their small size, can easily penetrate into the lower respiratory tract and can carry the virus directly into the alveoli and tracheobronchial region (Qu et al. 2020). Several studies have proven that air pollutants act as a carrier to transmit virus reducing the level of immune system and therefore make human bodies more vulnerable to virus infection (Becker and Soukup

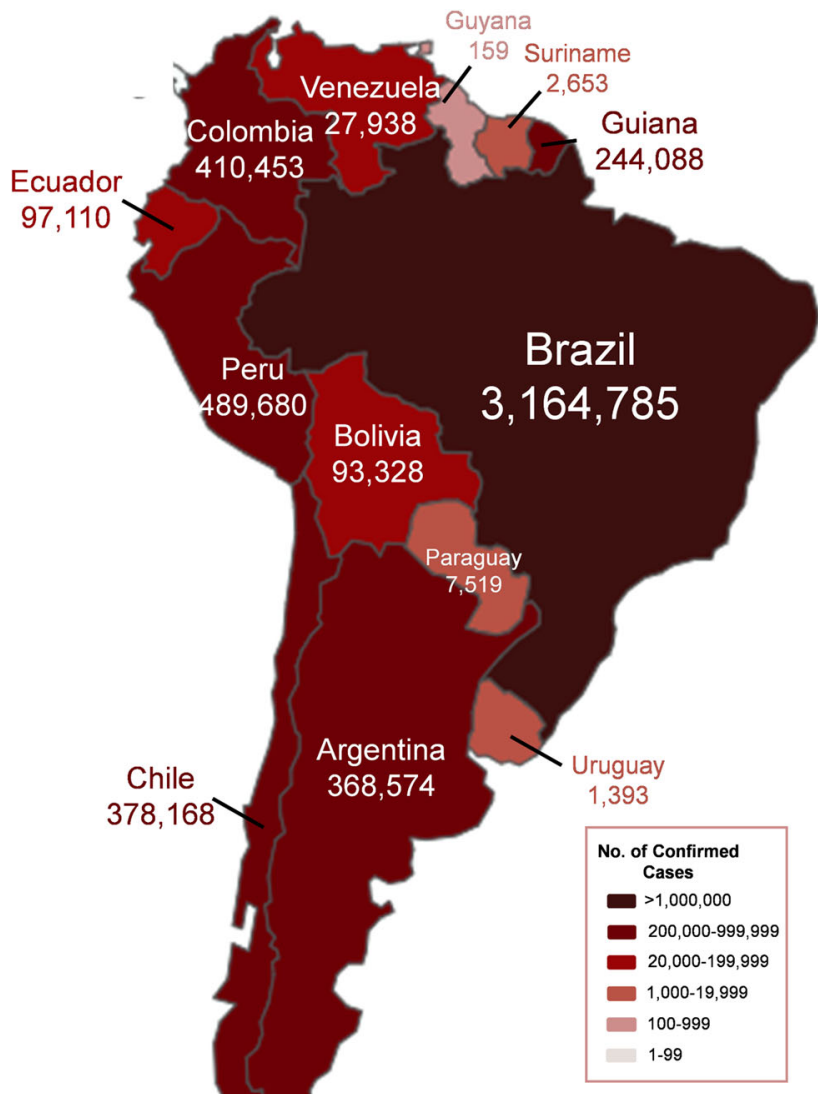

Statistics as of August 13

Fig. 1 Confirmed cases of COVID-19 across South America until 13 August, 2020. Data of coronavirus disease 2019 (COVID-19) from https://www.jhu.edu/
1999, Glencross et al. 2020, Xie et al. 2019, Xu et al. 2020). Air pollutants have been shown to affect the transmission and severity of respiratory viral infections including, but not limited to severe acute respiratory syndrome (SARS), the emergence of the Middle East respiratory syndrome (MERS), as well as SARS-CoV-2 (Cui et al. 2003; Domingo and Rovira 2020; Silva et al. 2014). It has been shown that air pollution is positively correlated with the mortality of SARS in China (Cui et al. 2003). The environment around us is filled with contaminants that can inadvertently expose humans to viruses (Daraei et al. 2020). Although risk factors for COVID-19 are still under investigation, it is possible that environmental factors, such as air pollution, may play a significant role in affecting the spread of the epidemic among the population.

In terms of SARS-CoV-2, multiple studies are showing the significant association between air pollution and the spread rate of the COVID-19. Several recent studies have shown that the risk is significantly higher for individuals contracting COVID-19 where they are exposed to environmental pollutants (Coccia 2021; Liu et al. 2021). Generalized additive models (GAM) showed that six air pollutants $\left(\mathrm{PM}_{2.5}, \mathrm{PM}_{10}\right.$, $\mathrm{SO}_{2}, \mathrm{CO}, \mathrm{NO}_{2}$, and $\mathrm{O}_{3}$ ) were significantly related to the confirmed cases in 120 cities from Jan 23 to Feb 29, 2020 in China. Empirical estimates suggested that $\mathrm{PM}_{2.5}$ is a significant factor associated with the COVID-19 pandemic in the top 10 most affected states in the USA (Bilal et al. 2021b). In Europe, the most severely affected region is the same as that possessed the highest concentrations of $\mathrm{PM}_{10}$ and $\mathrm{PM}_{2.5}$ (Martelletti and Martelletti 2020). Furthermore, most fatality cases occurred in the regions with the highest $\mathrm{NO}_{2}$ concentration (Ogen 2020). Spearman correlation analysis indicated that $\mathrm{PM}_{2.5}, \mathrm{O}_{3}$, and $\mathrm{NO}_{2}$ have a significant relationship with the outbreak of COVID-19 (Bilal et al. 2020). The relations were also confirmed in California, the USA, and India (Bashir et al. 2020c; Sharma et al. 2020). In South America, correlation analysis and wavelet transform coherence were used to explore the relationship between environmental pollution indicators and the spread of COVID-19. Results showed that $\mathrm{PM}_{10}, \mathrm{NO}_{2}, \mathrm{CO}$, and $\mathrm{O}_{3}$ are significant factors in the fight against the COVID-19 pandemic (Bilal et al. 2021a).

The impact of air pollution on the epidemic varies from study to study. Thus, the findings have been inconsistent and there were limited compelling reasons on the shape and magnitude of those relationships. Therefore, it is necessary to explore the effect of air pollution on the spread of COVID-19. Tracking the epidemic data and the dynamic variations of these values can help to estimate the spread of this emerging pandemic (Merl et al. 2009). Here, we assemble the datasets of the spread of the COVID-19 pandemic in five regions of South America. The time-dependent reproduction number $\left(R_{t}\right)$ in each area was estimated to assess the expected number of secondary cases arising from a primary case infected during the $t$ period (Thompson et al. 2019). The objective of this 
work is to assess the relationship of different air pollutants on the newly confirmed cases of COVID-19. To evaluate the impact of pollutants on epidemic spread more objectively and comprehensively, two frequently used models, generalized additive models (GAM) and multiple linear regression, were both applied to each city. And the results from both models were compared to explore the impact of air pollution on the spread of the COVID-19, in addition, we also compared the differences in the results of the two models.

\section{Materials and methods}

\section{Database of air pollutants and COVID-19 infection}

Five regions from three countries in South America, including Sao Paulo, Sao Jose dos Campos, and Vitoria in Brazil, Guayaquil in Ecuador, and Bogota in Colombia, were studied in this work. Time series data of air pollution including six major air pollutants $\mathrm{PM}_{2.5}, \mathrm{PM}_{10}, \mathrm{O}_{3}$, nitrogen dioxide $\left(\mathrm{NO}_{2}\right)$, sulfur dioxide $\left(\mathrm{SO}_{2}\right)$, and carbon monoxide $(\mathrm{CO})$ were obtained from real-time air quality index of Air Pollution in the World database (Data source: aqicn.org/data-platform/ covid19/). This website uses the standard for air pollutants from the US Environmental Protection Agency (EPA). And the daily air quality index (AQI) data were then converted to mass concentrations (https://www.airnow.gov/aqi/aqicalculator/AQICalculator|AirNow.gov). The data concerning the number of newly confirmed cases was collected directly from the National Health Department from March 28 to June 10, as it is shown in Table 1.

\section{Estimation of the time-dependent reproduction number $\left(R_{t}\right)$}

$R_{t}$, a time-dependent reproduction number, which can reflect the transmission of infectious diseases in the population (Cowling et al. 2010, Wallinga and Teunis 2004), was estimated with the f"EpiEstim" package in the R software. Based on the research of the Chinese CDC (Li et al. 2020b), we set an offset gamma distribution with mean of 7.5 days and standard deviation of 3.4 days. The smoothing time was set to 10 days. The epidemic grows when $R_{t}$ is above 1 and the outbreak will die out once $R_{t}$ stays below 1 . Cross-sectional analysis was performed to examine the spatial association between air pollutants and $R_{t}$ of COVID-19, and longitudinal analysis was used to examine the temporal associations of air pollutants with $R_{t}$.

\section{Statistical analysis}

To determine the relationship between each air pollutants, and the correlation between air pollutants and the transmission of COVID-19 $\left(R_{t}\right)$, we used Spearman correlation to assess the associations of air pollutants with $R_{t}$ with detection level $\alpha=$ 0.05 (bilateral). Based on the analysis of correlation, two frequently used models, multiple linear regression and generalized additive models (GAM), were both used in the study. For multiple linear regression model, the number of $R_{t}$ was used as dependent variables, and the daily air pollutants were selected as independent variables. The formula used was as follows:

$Y=\alpha+\beta_{1} X_{1}+\beta_{2} X_{2}+\cdots+\beta_{n} X_{n}$

In this model, the outcome variable, $Y$, is thought to be a linear function of a set of predictor variables, where $n$ is the number of predictor variables, $\alpha$ is a numerical constant that represents an intercept. $\beta$ s stands for the partial regression coefficients of $X$, each $\beta$ reflects that how $\mathrm{Y}$ will change with the $X$, which is associated with the $\beta$ when all other $X$ variables constant (Jaccard et al. 2006). Among them, Xs stand for the parameters of air pollution that are significantly associated with Rt.

GAM, developed by Hastie and Tibshirani (Hastie and Tibshirani 1995), was also used to estimate the association between $\mathrm{PM}_{2.5}, \mathrm{PM}_{10}, \mathrm{SO}_{2}, \mathrm{NO}_{2}, \mathrm{CO}$, and $R_{t}$. The fitting of GAM uses nonlinear smoothing term, the regression equation of GAM to predict a regressed variable is shown below:

$\mathrm{g}(\mathrm{E}(\mathrm{Y}))=\beta X_{1}+\sum_{i=2}^{p} S_{i}\left(X_{i}\right)$

where $Y$ is the predicted values of the dependent variable, $R_{t} ; X i$ represents the levels of air pollution, independent variables, and $S i$ is the nonparametric smoothing function.
Table 1 The source of daily confirmed cases of COVID-19

\begin{tabular}{lll}
\hline Country & Regions & Data sources \\
\hline Brazil & Sao Paulo & https://covid.saude.gov.br/ \\
& Sao Jose dos Campos & \\
& Vitoria & \\
Ecuador & Guayaquil & https://coronavirusecuador.com/data/ \\
Colombia & Bogota & https:/www.ins.gov.co/Noticias/Paginas/Coronavirus. \\
& & aspx \\
\hline
\end{tabular}


According to the different data distribution of dependent variables, different methods are used to fit the model. Popularly used distributions in GAM modeling are Normal, Gamma, and Poisson distributions (Ravindra et al. 2019). In this paper, we applied Poisson distributions to examine the moving average lag effect (7 days) of air pollutions on daily values of $R_{t}$ of COVID-19 and all Poisson regression analyses were performed in $\mathrm{R}$ (version 3.6.2) with the "mgcv" package.

\section{Results}

\section{Daily pollutant data}

As shown in Fig. 2 and Fig. S1, the median concentration of particulate matter in Sao Jose dos Campos $\left(\mathrm{PM}_{2.5}, 11.040 \mu \mathrm{g} /\right.$ $\left.\mathrm{m}^{3}, \mathrm{PM}_{10}, 19.440 \mu \mathrm{g} / \mathrm{m}^{3}\right), \mathrm{O}_{3}(0.020 \mathrm{ppm})$, and $\mathrm{CO}(6.453$ $\mathrm{ppb})$ in Colombia, $\mathrm{NO}_{2}(4.558 \mathrm{ppb})$ in Guayaquil and $\mathrm{SO}_{2}$ (10.706 ppb) in Sao Paulo were the highest within the five cities, respectively. The concentrations of other pollutants are at similar levels through these five cities. According to Spearman's correlation coefficient, there is a positive correlation between the six pollutants, most of which are extremely significant $(\mathrm{p}<0.01)$, except $\mathrm{O}_{3}$, which has a negative correlation, or weak positive correlation (in Vitoria) with other
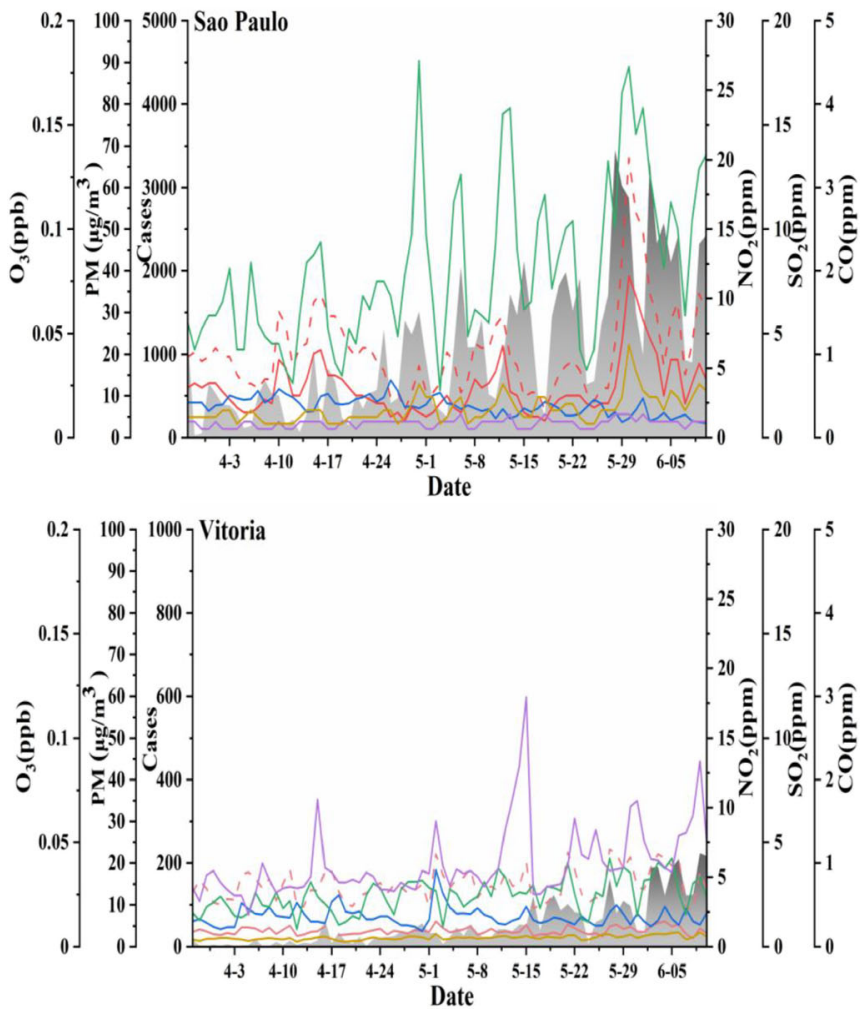

Fig. 2 Daily changes in the number of confirmed COVID-19 cases and air pollution in the selected regions. The gray areas indicate the number of daily confirmed cases. The colored lines represent the pollution changes pollutants in three Brazilian cities (Fig. 3A-3C). In Bogota (Fig. 3D), there are strong positive correlations $(\mathrm{p}<0.01)$ between each pollutant, except $\mathrm{O}_{3} / \mathrm{NO}_{2}, \mathrm{SO}_{2} / \mathrm{CO}$. In Guayaquil (Fig. 3E), the correlation between any of the two pollutants is statistically significant $(\mathrm{p}<0.05)$.

\section{Epidemiological data in the selected regions}

The calculated $R_{t}$ (Fig. 4) values showed a gradual decline in all the five regions, particularly in Sao Jose dos Campos, where the peak was 5.56, and then went down to 1.16 on June 10. The $R_{t}$ value of Guayaquil decreased from the peak of 1.72 to 0.24 . By contrast, $R_{t}$ in Victoria fluctuated, and it remained above 1 until June 10, indicating that the epidemic situation in the region was still serious.

\section{Model fitting}

The results of GAM and multiple linear models are shown in Fig. 5, Figs. S2-S4, and Table 2, respectively. By establishing GAM models between the pollutant factors (explanatory variables) and the $R_{t}$ response variables, the smooth regression function of explanatory variables is obtained, as well as the effect diagram of influencing factors on $R_{t}$ (Fig. 5 and Figs. S2-S4). The results show that there is a nonlinear relationship
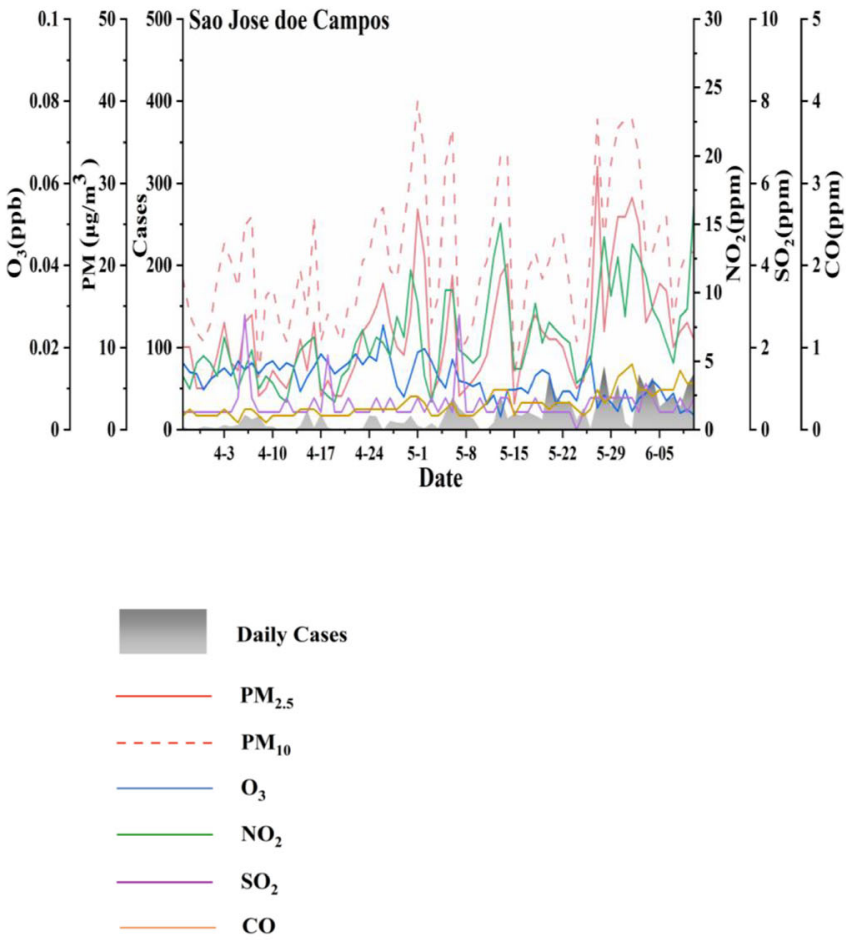

over the corresponding time, the red line represents $\mathrm{PM}_{2.5}$, the dashed line represents $\mathrm{PM}_{10}$, the blue line represents $\mathrm{O}_{3}$, the green line represents $\mathrm{NO}_{2}$, the purple line represents $\mathrm{SO}_{2}$, and the orange line represents $\mathrm{CO}$ 


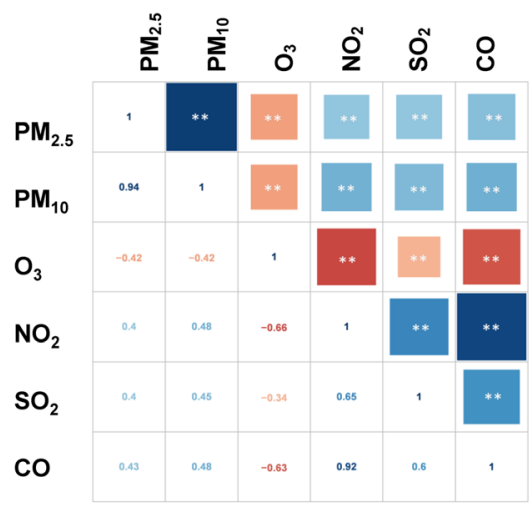

A. Sao Paulo

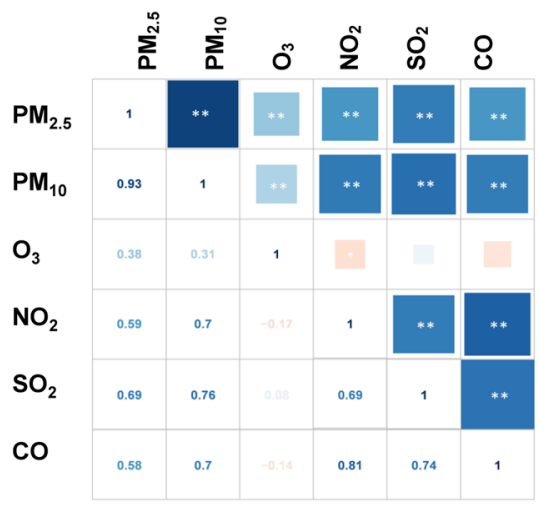

D. Bogota

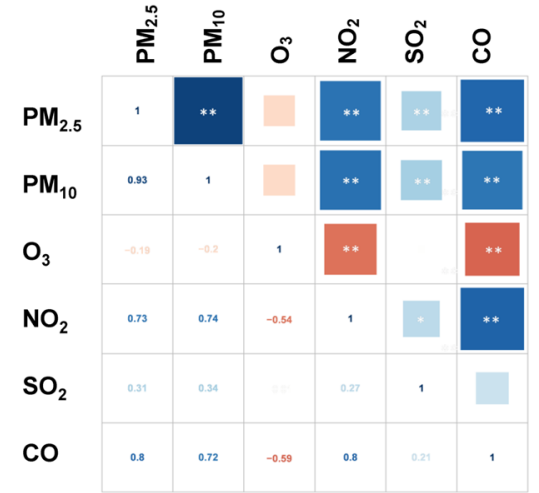

B. Sao Joes dos Campos

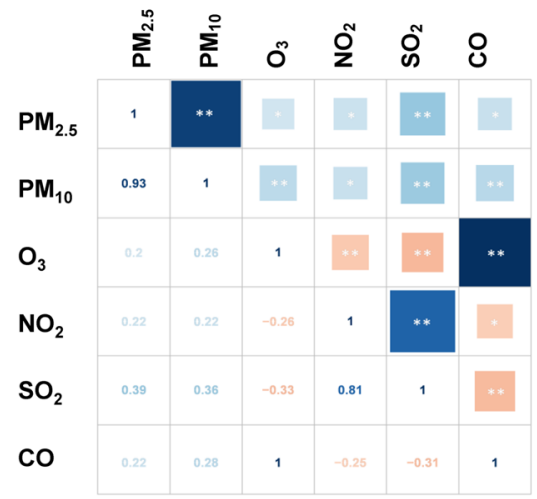

E. Guayaquil

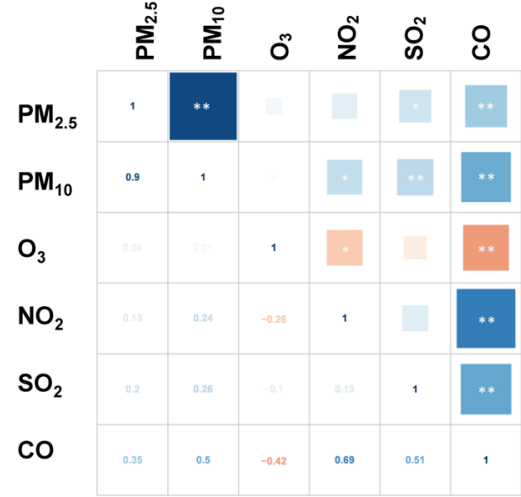

C. Vitoria

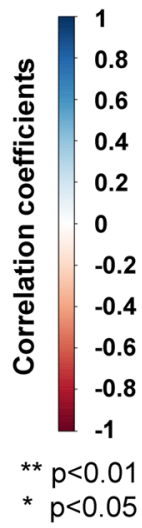

Fig. 3 Spearman correlation between air pollution and $R_{t}$ in the five regions. The color gradient indicated Spearman's correlation coefficients. The darker blue indicates a stronger positive correlation,

and darker red indicates a stronger negative correlation. Data significance was marked by $* \mathrm{p}<0.05, * * \mathrm{p}<0.01$
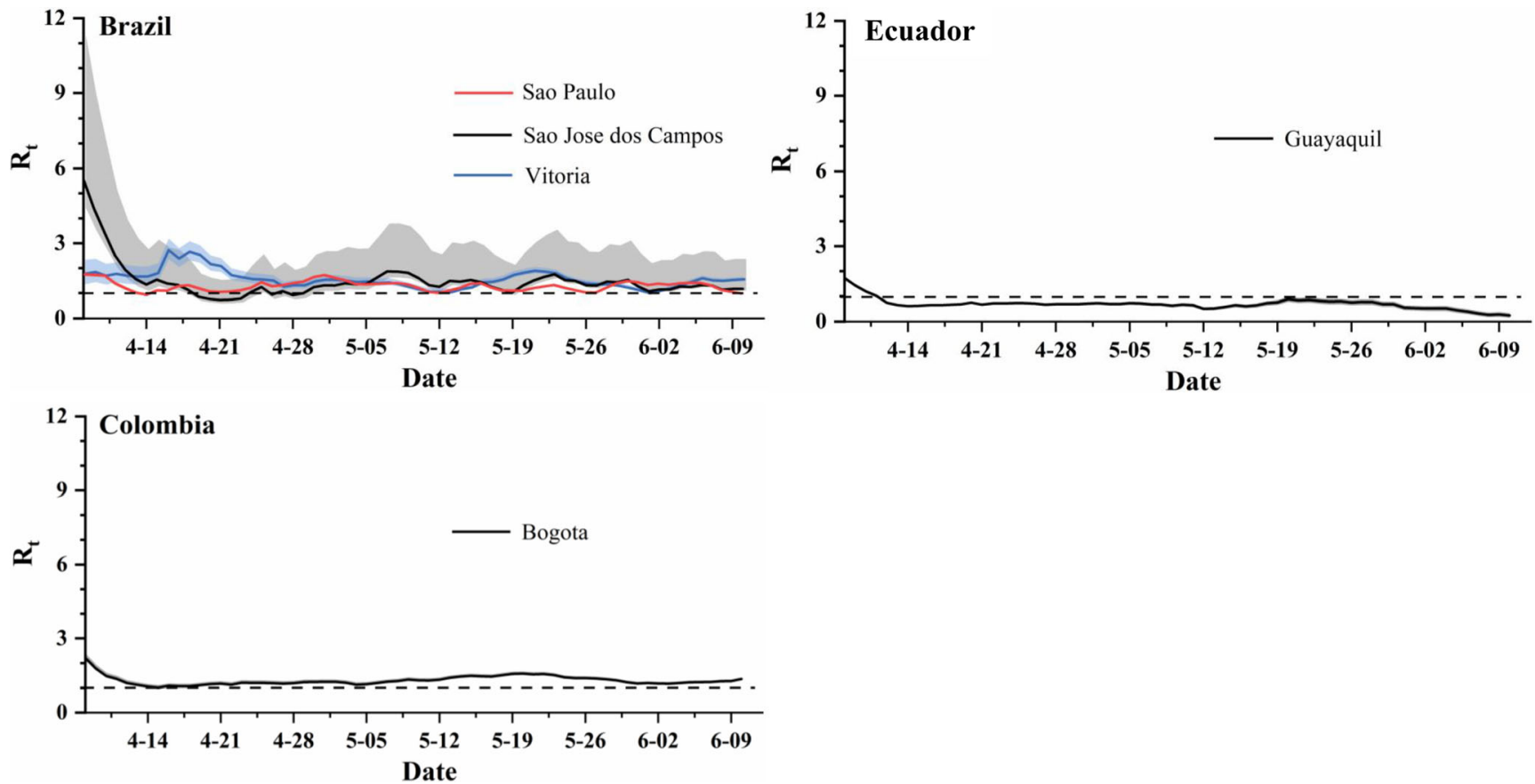

Fig. 4 Daily estimated distributions of the effective reproduction number $R_{t}$, based on selected epidemiological data for COVID-19 with $95 \%$ confidence intervals, where the dashed line represents the threshold of $R_{t}$ 

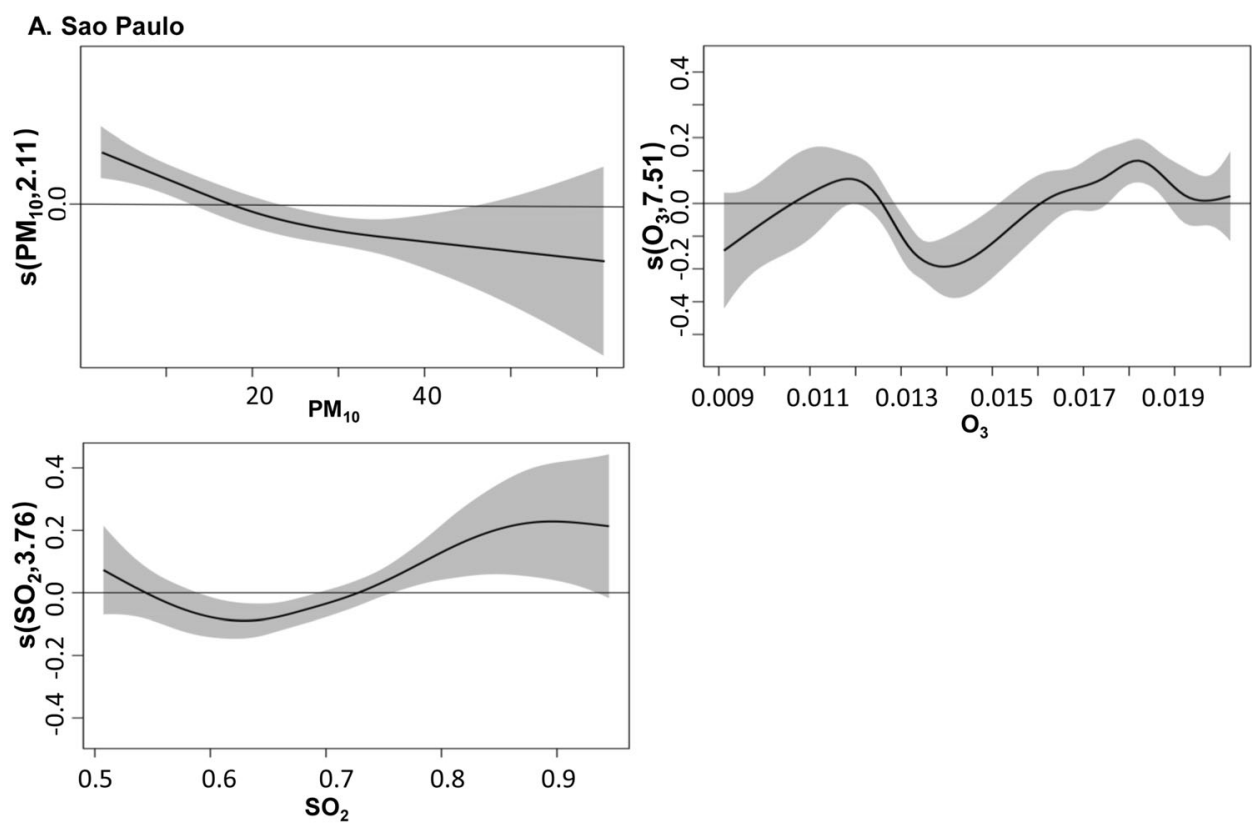

B. Sao Jose dos Campos
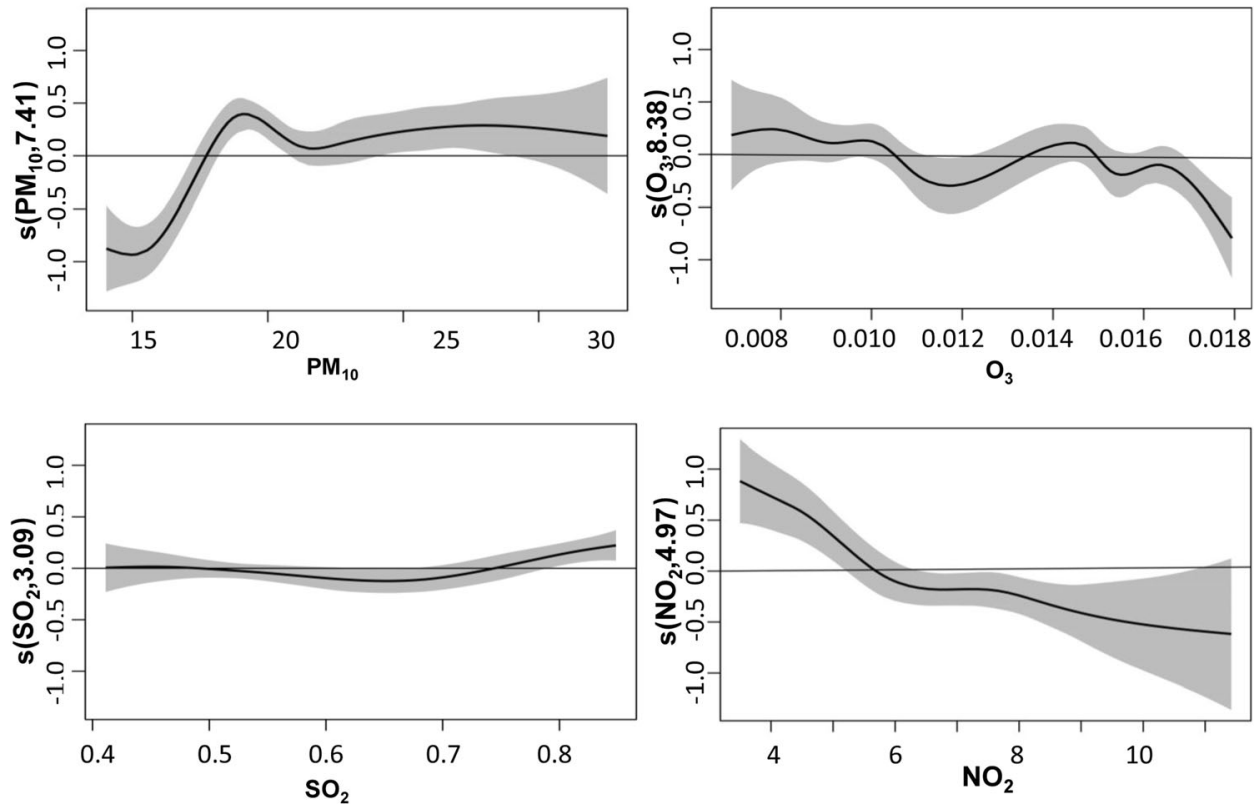

Fig. 5 The results of the GAM model for the effects of air pollutants on the variation of $R_{t}$. The gray areas represent the upper and lower limits of the confidence intervals for fitting additive functions, the solid lines represent the smooth fitting curves of $R_{t}$, and the horizontal coordinates

represent the measured values of the explanatory variables, ordinate represents the smooth fitting of explanatory variables to $R_{t}$ ordinate values in parentheses represent estimated degrees of freedom

between $R_{t}$ and each explanatory variable in Sao Paulo (Fig. $5 \mathrm{~A}$ ), and $R_{t}$ value decreases gradually with the increase of $\mathrm{PM}_{10}$ concentration. $R_{t}$ increases monotonically when $\mathrm{O}_{3}$ concentration is less than $0.012 \mathrm{ppm}$ or between $0.014 \mathrm{ppm}$ and $0.018 \mathrm{ppm}$. When $\mathrm{SO}_{2}$ concentration is less than $0.6 \mathrm{ppb}, R_{t}$ shows a slowly decreasing trend. However, $R_{t}$ increases with the elevation of $\mathrm{SO}_{2}$ when $\mathrm{SO}_{2}$ concentration is higher than 0.6 ppb. In Sao Jose dos Campos (Fig. 5B), $R_{t}$ shows an increasing

trend when $\mathrm{PM}_{10}$ concentration is between $15 \mu \mathrm{g} / \mathrm{m}^{3}$ and 20 $\mu \mathrm{g} / \mathrm{m}^{3}$. And $R_{t}$ shows a fluctuating downward trend with the increase of $\mathrm{O}_{3}$ and $\mathrm{NO}_{2}$ concentration, and a weak change with the increase of $\mathrm{SO}_{2}$ concentration. In Victoria (Fig. S2), $R_{t}$ shows a fluctuating downward trend with the increase of $\mathrm{PM}_{10}$ and $\mathrm{NO}_{2}$ concentrations. When $\mathrm{O}_{3}$ concentration is less than $0.012 \mathrm{ppm}, R_{t}$ decreases gradually; when $\mathrm{O}_{3}$ concentration is higher than $0.012 \mathrm{ppm}, R_{t}$ changes relatively gently. $R_{t}$ shows 
Table 2 Summary of the models

\begin{tabular}{lll}
\hline Region & Model & Significant independent variables \\
\hline Sao Paulo & GAM & $\mathrm{PM}_{10}, \mathrm{SO}_{2}, \mathrm{O}_{3}$ \\
& Multiple linear regression & $\mathrm{SO}_{2}, \mathrm{O}_{3}$ \\
Sao joe dos Campos & GAM & $\mathrm{PM}_{10}, \mathrm{SO}_{2}, \mathrm{NO}_{2}, \mathrm{O}_{3}$ \\
& Multiple linear regression & $/$ \\
Vitoria & GAM & $\mathrm{PM}_{10}, \mathrm{SO}_{2}, \mathrm{CO}, \mathrm{NO}_{2}, \mathrm{O}_{3}$ \\
& Multiple linear regression & $\mathrm{SO}_{2}, \mathrm{NO}_{2}$ \\
Bogota & GAM & $\mathrm{PM}_{10}, \mathrm{SO}_{2}, \mathrm{CO}, \mathrm{NO}_{2}, \mathrm{O}_{3}$ \\
& Multiple linear regression & $\mathrm{PM}_{10}$ \\
Guayaquil & GAM & $\mathrm{PM}_{10}, \mathrm{SO}_{2}, \mathrm{CO}, \mathrm{O}_{3}$ \\
\hline
\end{tabular}

Multiple linear regression/

/, no significant independent variables in the model

a large fluctuating change when the $\mathrm{SO}_{2}$ concentration is below $4.0 \mathrm{ppb}$ and almost no significant change when it is higher than $4 \mathrm{ppb} . R_{t}$ increases monotonically when $\mathrm{CO}$ concentration is higher than $0.11 \mathrm{ppb}$. In Bogota (Fig. S3), with the increase of $\mathrm{PM}_{10}$ and $\mathrm{NO}_{2}$ concentration, $R_{t}$ shows a certain fluctuation, but the value does not change a lot. When the $\mathrm{O}_{3}$ concentration is less than $0.004 \mathrm{ppm}, R t$ shows a monotonically increasing trend, while it decreases as the $\mathrm{O}_{3}$ concentration rises above $0.008 \mathrm{ppm}$. When $\mathrm{SO}_{2}$ concentration is less than $0.35 \mathrm{ppb}, R_{t}$ tends to decrease slowly, while when it is higher than this concentration, $R_{t}$ increases gradually. $R_{t}$ shows a fluctuating rising trend with the increase of $\mathrm{CO}$ concentration. When $\mathrm{CO}$ concentration was higher than $0.42 \mathrm{ppb}$, there is no obvious change. In Guayaquil (Fig. S4), $R_{t}$ decreases slowly when the concentration of $\mathrm{PM}_{10}$ is lower than $17 \mu \mathrm{g} / \mathrm{m}^{3}$ and increases slowly when it is higher than $17 \mu \mathrm{g} / \mathrm{m}^{3}$. Rt increases when the $\mathrm{O}_{3}$ concentration is less than $0.03 \mathrm{ppm}$ and decreases above $0.03 \mathrm{ppm} . R_{t}$ value shows a relatively slow change with the increase of $\mathrm{SO}_{2}$ concentration. The correlation between $\mathrm{CO}$ concentration and $R t$ shows a certain linear relationship, and when $\mathrm{CO}$ concentration increases, $R_{t}$ decreases monotonically.

However, based on the results of multiple linearity (Table 3), the magnitudes of $\beta$ reflect the influence of the corresponding variable, there is a positive correlation between the $R_{t}$ value and $\mathrm{O}_{3}(\beta=13.135)$ in Sao Paulo and a negative correlation with $\mathrm{SO}_{2}(\beta=-0.320)$. In Victoria, $R_{t}$ was negatively correlated with $\mathrm{NO}_{2}(\beta=-0.147)$ and $\mathrm{SO}_{2}(\beta=-0.053)$.
There is a negative correlation between $R_{t}$ and $\mathrm{PM}_{10}$ in Bogota $(\beta=-0.013)$. For Sao Jose dos Campos and Guayaquil, there is no linear correlation.

\section{Discussion}

In this study, we analyzed the relationship between COVID19 infection and air pollution in five regions of South America. Our data spans a wider range of time and space and more types of pollutants than previous studies. And referred to the previous studies, two frequently used models, generalized additive models (GAM) and multiple linear regression, were both used for each city. At the same time, the results of the two models in the same region were different. According to our results, $R t$ responds to different air pollutants $\left(\mathrm{PM}_{2.5}, \mathrm{PM}_{10}, \mathrm{O}_{3}, \mathrm{SO}_{2}, \mathrm{NO}_{2}, \mathrm{CO}\right)$ in different regions. Although the same significant factors were not obtained using the multiple linear regression model, however, the GAM model showed that $\mathrm{PM}_{10}$ and $\mathrm{SO}_{2}$ responded significantly to $R_{t}$ in all regions. Previous study shows that COVID-19 confirmed cases is significantly positively associated with $\mathrm{PM}_{2.5}, \mathrm{PM}_{10}$, $\mathrm{CO}$, and $\mathrm{NO}_{2}$, and negatively associated with $\mathrm{SO}_{2}$ by using the GAM model (Liu et al. 2021). And research on the spread of COVID-19 and environmental quality showed that $\mathrm{PM}_{10}$, $\mathrm{NO}_{2}, \mathrm{CO}$, and $\mathrm{O}_{3}$ are significant factors in the fight against the COVID-19 pandemic in South America (Bilal et al. 2021a).
Table 3 Statistical data of the multiple linear regression equation

\begin{tabular}{llll}
\hline Region & Model formula & $\mathbf{R}^{\mathbf{2}}$ & ${\text { Adjusted } \mathbf{R}^{2}}^{2}$ \\
\hline Sao Paulo & $\mathrm{Y}_{\mathrm{Rt}}=1.163+13.135 \mathrm{X}_{\mathrm{O} 3}-0.320 \mathrm{X}_{\mathrm{SO} 2}$ & 0.142 & 0.069 \\
Sao Jose dos Campos & $/$ & $/$ & $/$ \\
Vitoria & $\mathrm{Y}_{\mathrm{Rt}}=2.120-0.148 \mathrm{X}_{\mathrm{NO} 2}-0.053 \mathrm{X}_{\mathrm{SO} 2}$ & 0.306 & 0.246 \\
Bogota & $\mathrm{Y}_{\mathrm{Rt}}=1.257-0.013 \mathrm{X}_{\mathrm{PM} 10}$ & 0.182 & 0.111 \\
Guayaquil & $/$ & $/$ & $/$ \\
\hline
\end{tabular}


Table 4 Comparison of correlational studies between air pollution and COVID-19 in various studies

\begin{tabular}{|c|c|c|c|c|}
\hline Environment variable & Date range & Region & Model & Reference \\
\hline $\mathrm{PM}_{2.5}, \mathrm{PM}_{10}, \mathrm{NO}_{2}, \mathrm{CO}$ & Jan 26th to Feb 29th & Hubei, China & Linear regression & (Li et al. 2020a) \\
\hline $\mathrm{PM}_{2.5}$ & Mar 1st to Apr 20th & New York City, America & Negative binomial regression & $\begin{array}{l}\text { (Adhikari and Yin } \\
\text { 2020) }\end{array}$ \\
\hline $\mathrm{PM}_{2.5}, \mathrm{PM}_{10}, \mathrm{SO}_{2}, \mathrm{CO}, \mathrm{NO}_{2}, \mathrm{O}_{3}$ & Jan 23th to Feb 29th & 120 cities, China & GAM & \\
\hline $\begin{array}{l}\mathrm{PM}_{2.5}, \mathrm{PM}_{10}, \mathrm{SO}_{2}, \mathrm{VOC}, \mathrm{CO}, \mathrm{NO}_{2}, \\
\mathrm{~Pb}\end{array}$ & Mar 4th to Apr 24th & California, America & $\begin{array}{l}\text { Spearman and Kendall } \\
\text { correlation }\end{array}$ & (Bashir et al. 2020a) \\
\hline $\mathrm{PM}_{2.5}, \mathrm{PM}_{10}$ & Jan 15 th to Feb 29th & Hubei, China & Spatial auto-correlation statistics & (Yao et al. 2020) \\
\hline $\mathrm{PM}_{2.5}, \mathrm{PM}_{10}, \mathrm{SO}_{2}, \mathrm{CO}, \mathrm{NO}_{2}, \mathrm{O}_{3}$ & Jan 25th to Feb 29th & Hubei, China & Multivariate Poisson regression & (Jiang et al. 2020) \\
\hline $\mathrm{PM}_{2.5}, \mathrm{NO}_{2}$ & Feb to Mar & Italy & Pearson correlation & (Frontera et al. 2020) \\
\hline $\mathrm{PM}_{2.5}, \mathrm{PM}_{10}, \mathrm{NO}_{2}, \mathrm{O}_{3}$ & Feb 24th to Jul 2nd & Germany & Spearman correlation & (Bilal et al. 2020) \\
\hline $\mathrm{PM}_{2.5}$ & $\begin{array}{l}\text { Mar 2nd to } \\
\text { Sept 17th }\end{array}$ & the USA & $\begin{array}{l}\text { Spearman and Kendall } \\
\text { correlation }\end{array}$ & (Bilal et al. 2021b) \\
\hline $\mathrm{PM}_{2.5}, \mathrm{PM}_{10}, \mathrm{SO}_{2}, \mathrm{CO}, \mathrm{NO}_{2}, \mathrm{O}_{3}$ & Jan 22 nd to Oct 8 th & $\begin{array}{l}\text { South American capital } \\
\text { cities }\end{array}$ & Kendall correlation & (Bilal et al. 2021a) \\
\hline $\mathrm{PM}_{2.5}, \mathrm{PM}_{10}, \mathrm{SO}_{2}, \mathrm{CO}, \mathrm{NO}_{2}, \mathrm{O}_{3}$ & $\begin{array}{l}\text { Jan 28th to } \\
\text { May 31st }\end{array}$ & China & Regression discontinuity design & (Liu et al. 2021) \\
\hline $\mathrm{PM}_{2.5}, \mathrm{PM}_{10}, \mathrm{SO}_{2}, \mathrm{CO}, \mathrm{NO}_{2}, \mathrm{O}_{3}$ & $\begin{array}{l}\text { Mar 28th to } \\
\text { Jun 10th }\end{array}$ & South America & GAM, multiple linear regression & This study \\
\hline
\end{tabular}

I, no model in the study

Our findings are partially consistent with these results. Currently, there are limited studies on air pollution and the spread of COVID, and conclusions are differing. There may be regional differences that could have a potential impact on the epidemic transmission, including variation in the timing and coverage of public health interventions (Dalziel et al. 2018). Due to different environmental conditions, even the impact of the same pollutant will vary. We pooled data from similar studies in the past, and summarized the types of pollutants, the study areas, the study time, and the fitting model used (Table 4). All results show that air pollutants are significantly correlated with the spread of COVID-19. Furthermore, there were differences in the results from different study areas, times of coverage, and models used.

Although currently there are some analytical findings, we offer the following limitations in our research work. Our findings do not reveal a clear effect of pollutants on the virus's ability to spread, but our data are broader in space and time than previous studies, and more diverse than most studies. This can give an indication that the effects of pollutants on disease may not be specific, and the results of GAM and multiple linear model in individual cities cannot be directly replicated in other regions. There are shortcomings in the currently used models. The conclusions drawn from a single fitting result cannot be directly applied, and more models can be used in future research.

There are some limitations of this study. First, there may be differences in the timing of the acquisition of epidemic data across regions. Thus, we encourage further research to analyze the association of environmental indicators with COVID-19 transmission in a wider range of regions to provide more important insights. Second, there are many other models for this kind of prediction. In this paper, GAM and multiple linear models are adopted, and there may be other more appropriate models. Third, there are many other factors that contribute to outbreaks of COVID-19, such as individual behavior, government control measures, urban density, and population. In this paper, only air pollution is considered. Social intervention, as well as population immunity, may have a greater impact on the virus's ability to spread compared to air pollution (Baker et al. 2020). Future research needs to investigate the impact of social intervention, urban density, and population.

\section{Conclusion}

Over the past few months, the South American region has become the central region of the COVID-19 pandemic, as the infection rate of COVID-19 has been increasing. The current work investigates six environmental pollutants in South America and their association with the COVID-19 pandemic in the region. According to the experiments and analysis results, this study has come to the following conclusions:(1) $R_{t}$, which can reflect the spread of COVID-19, showed a gradual decline in all the five regions. (2) $\mathrm{PM}_{10}$ and $\mathrm{SO}_{2}$ responded significantly to $R_{t}$ in all selected regions. Regulators should make better monitoring of these two pollutants. (3) The association between air pollution and the spread of COVID-19 
differed in varied cities with specific statuses of air pollution. Inconsistent results were obtained from GAM and multiple linear regression model for one city. For example, in Sao Jose dos Campos, GAM revealed that the four air pollutants $\mathrm{PM}_{10}, \mathrm{SO}_{2}, \mathrm{NO}_{2}$, and $\mathrm{O}_{3}$ were significantly related to the spread of COVID-19. However, the multiple linear regression model showed that air pollution is not significantly related to the spread of COVID-19. There remains a need to optimize models to assess the contribution of air pollution to the COVID-19 pandemic. As well, more regions need to be studied to reveal the association of air pollution to the spread of COVID-19. Future research should take a comprehensive approach, including consideration of epidemiological aspects, socio-economic issues, and the different lockdowns and mobility restrictions imposed by each country.

Supplementary Information The online version contains supplementary material available at https://doi.org/10.1007/s11356-021-15508-8.

Availability of data and materials The datasets used and/or analyzed during the current study are available from the corresponding author on reasonable request.

Author contribution Haining Huang: conceptualization, methodology, visualization, writing. Congtian Lin: conceptualization, methodology, visualization, Writing. Xiaobo Liu: methodology, data collection. Liting Zhu: data collection, visualization. Ricardo David Avellán-Llaguno: data collection, critical revision. Mauricio Manuel Llaguno Lazo: data collection, critical revision. Xiaoyan Ai: study conception, drafting. Qiansheng Huang: study conception, analysis and interpretation of data, drafting.

Funding This work was supported by the Strategic Priority Research Program of the Chinese Academy of Sciences (XDA19090115), Bureau of International Cooperation Chinese Academy of Sciences (132C35KYSB20200012), and the Youth Innovation Promotion Association CAS (2018343).

\section{Declarations}

Ethics approval Not applicable.

Consent to participate Not applicable.

Consent for publication Not applicable.

Competing interests The authors declare no competing interests.

\section{References}

Adhikari A, Yin J (2020) Short-term effects of ambient ozone, PM2.5, and meteorological factors on COVID-19 confirmed cases and deaths in Queens, New York. Int J Environ Res Public Health 17(11):4047. https://doi.org/10.3390/ijerph17114047

Anfinrud P, Stadnytskyi V, Bax CE, Bax A (2020) Visualizing speechgenerated oral fluid droplets with laser light scattering. N Engl J Med 382:2061-2063
Baker RE, Yang W, Vecchi GA, Metcalf CJE, Grenfell BT (2020) Susceptible supply limits the role of climate in the early SARSCoV-2 pandemic. Science (New York, N.Y.). 369(6501):315-319. https://doi.org/10.1126/science.abc2535

Bashir MF, Ma B, Bilal KB, Bashir MA, Tan D, Bashir M (2020a) Correlation between climate indicators and COVID-19 pandemic in New York, USA. Sci Total Environ 728:138835

Bashir MF, Ma B, Shahzad L (2020b) A brief review of socio-economic and environmental impact of Covid-19. Air Qual Atmos Health:1-7. https://doi.org/10.1007/s11869-020-00894-8

Bashir MF, Ma BJ, Bilal KB, Bashir MA, Farooq TH, Iqbal N, Bashir M (2020c) Correlation between environmental pollution indicators and COVID-19 pandemic: a brief study in Californian context. Environ Res 187:109652

Becker S, Soukup JM (1999) Exposure to urban air particulates alters the macrophage-mediated inflammatory response to respiratory viral infection. J Toxicol Environ Health A 57:445-457

Bell ML, Davis DL, Fletcher T (2004) A retrospective assessment of mortality from the London smog episode of 1952: the role of influenza and pollution. Environ Health Perspect 112:6-8

Bilal BMF, Benghoul M, Numan U, Shakoor A, Komal B, Bashir MA, Bashir M, Tan D (2020) Environmental pollution and COVID-19 outbreak: insights from Germany. Air Qual Atmos Health:1-10. https://doi.org/10.1007/s11869-020-00893-9

Bilal BMF, Komal B, Benghoul M, Bashir MA, Tan D (2021a) Nexus between the COVID-19 dynamics and environmental pollution indicators in South America. Risk Manag Healthc Policy 14:67-74

Bilal BMF, Shahzad K, Komal B, Bashir MA, Bashir M, Tan D, Fatima T, Numan U (2021b) Environmental quality, climate indicators, and COVID-19 pandemic: insights from top 10 most affected states of the USA. Environ Sci Pollut Res Int 28:32856-32865

Chan JF et al (2020) A familial cluster of pneumonia associated with the 2019 novel coronavirus indicating person-to-person transmission: a study of a family cluster. Lancet 395:514-523

Chen N, Zhou M, Dong X, Qu J, Gong F, Han Y, Qiu Y, Wang J, Liu Y, Wei Y, Xia J, Yu T, Zhang X, Zhang L (2020) Epidemiological and clinical characteristics of 99 cases of 2019 novel coronavirus pneumonia in Wuhan, China: a descriptive study. Lancet 395:507-513

Coccia M (2021) Effects of the spread of COVID-19 on public health of polluted cities: results of the first wave for explaining the deja vu in the second wave of COVID-19 pandemic and epidemics of future vital agents. Environ Sci Pollut Res Int 28:19147-19154

Cowling BJ, Lau MS, Ho LM, Chuang SK, Tsang T, Liu SH, Leung PY, Lo SV, Lau EH (2010) The effective reproduction number of pandemic influenza: prospective estimation. Epidemiology 21:842-846

Cui Y, Zhang ZF, Froines J, Zhao J, Wang H, Yu SZ, Detels R (2003) Air pollution and case fatality of SARS in the People's Republic of China: an ecologic study. Environ Health 2:15

Dalziel BD, Kissler S, Gog JR, Viboud C, Bjørnstad ON, Metcalf C, Grenfell BT (2018) Urbanization and humidity shape the intensity of influenza epidemics in U.S. cities. Science (New York, N.Y.) 362(6410):75-79. https://doi.org/10.1126/science.aat6030

Daraei H, Toolabian K, Kazempour M, Javanbakht M (2020) The role of the environment and its pollution in the prevalence of COVID-19. J Inf Secur 81:e168-e169

Domingo JL, Rovira J (2020) Effects of air pollutants on the transmission and severity of respiratory viral infections. Environ Res 187:109650

Frontera A, Cianfanelli L, Vlachos K, Landoni G, Cremona G (2020) Severe air pollution links to higher mortality in COVID-19 patients: The "double-hit" hypothesis. J Inf Secur 81:255-259

Glencross DA, Ho TR, Camina N, Hawrylowicz CM, Pfeffer PE (2020) Air pollution and its effects on the immune system. Free Radic Biol Med 151:56-68

Goings SA, Kulle TJ, Bascom R, Sauder LR, Green DJ, Hebel JR, Clements ML (1989) Effect of nitrogen dioxide exposure on 
susceptibility to influenza A virus infection in healthy adults. Am Rev Respir Dis 139:1075-1081

Hashim BM, Al-Naseri SK, Al Maliki A, Sa'adi Z, Malik A, Yaseen ZM (2021) On the investigation of COVID-19 lockdown influence on air pollution concentration: regional investigation over eighteen provinces in Iraq. Environ Sci Pollut Res Int

Hastie T, Tibshirani R (1995) Generalized additive models for medical research. Stat Methods Med Res 4:187-196

Jaccard J, Guilamo-Ramos V, Johansson M, Bouris A (2006) Multiple regression analyses in clinical child and adolescent psychology. $\mathrm{J}$ Clin Child Adolesc Psychol 35:456-479

Jiang Y, Wu XJ, Guan YJ (2020) Effect of ambient air pollutants and meteorological variables on COVID-19 incidence. Infect Control Hosp Epidemiol 41(9):1011-1015

Li H, Xu XL, Dai DW, Huang ZY, Ma Z, Guan YJ (2020a) Air pollution and temperature are associated with increased COVID-19 incidence: A time series study. Int J Infect Dis 97:278-282

Li Q, Guan X, Wu P, Wang X, Zhou L, Tong Y, Ren R, Leung KSM, Lau EHY, Wong JY, Xing X, Xiang N, Wu Y, Li C, Chen Q, Li D, Liu T, Zhao J, Liu M, Tu W, Chen C, Jin L, Yang R, Wang Q, Zhou S, Wang R, Liu H, Luo Y, Liu Y, Shao G, Li H, Tao Z, Yang Y, Deng Z, Liu B, Ma Z, Zhang Y, Shi G, Lam TTY, Wu JT, Gao GF, Cowling BJ, Yang B, Leung GM, Feng Z (2020b) Early transmission dynamics in Wuhan, China, of novel coronavirus-infected pneumonia. N Engl J Med 382:1199-1207

Liu Y, Ning Z, Chen Y, Guo M, Liu Y, Gali NK, Sun L, Duan Y, Cai J, Westerdahl D, Liu X, Xu K, Ho KF, Kan H, Fu Q, Lan K (2020) Aerodynamic analysis of SARS-CoV-2 in two Wuhan hospitals. Nature 582:557-560

Liu Q, Xu S, Lu X (2021) Association between air pollution and COVID19 infection: evidence from data at national and municipal levels. Environ Sci Pollut Res 28:37231-37243

Lu R, Zhao X, Li J, Niu P, Yang B, Wu H, Wang W, Song H, Huang B, Zhu N, Bi Y, Ma X, Zhan F, Wang L, Hu T, Zhou H, Hu Z, Zhou W, Zhao L, Chen J, Meng Y, Wang J, Lin Y, Yuan J, Xie Z, Ma J, Liu WJ, Wang D, Xu W, Holmes EC, Gao GF, Wu G, Chen W, Shi W, Tan W (2020) Genomic characterisation and epidemiology of 2019 novel coronavirus: implications for virus origins and receptor binding. Lancet 395:565-574

Martelletti L, Martelletti P (2020) Air pollution and the novel covid-19 disease: a putative disease risk factor. SN Compr Clin Med:1-5

Merl D, Johnson LR, Gramacy RB, Mangel M (2009) A statistical framework for the adaptive management of epidemiological interventions. PLoS One 4:e5807

Meselson M (2020) Droplets and aerosols in the transmission of SARSCoV-2. N Engl J Med 382:2063
Ogen Y (2020) Assessing nitrogen dioxide (NO2) levels as a contributing factor to coronavirus (COVID-19) fatality. Sci Total Environ 726: 138605

Qu G, Li X, Hu L, Jiang G (2020) An imperative need for research on the role of environmental factors in transmission of novel coronavirus (COVID-19). Environ Sci Technol 54:3730-3732

Ravindra K, Rattan P, Mor S, Aggarwal AN (2019) Generalized additive models: building evidence of air pollution, climate change and human health. Environ Int 132:104987

Sharma S, Zhang M, Anshika GJ, Zhang H, Kota SH (2020) Effect of restricted emissions during COVID-19 on air quality in India. Sci Total Environ 728:138878

Silva DR, Viana VP, Muller AM, Livi FP, Dalcin Pde T (2014) Respiratory viral infections and effects of meteorological parameters and air pollution in adults with respiratory symptoms admitted to the emergency room. Influenza Other Respir Viruses 8:42-52

Thompson RN, Stockwin JE, van Gaalen RD, Polonsky JA, Kamvar ZN, Demarsh PA, Dahlqwist E, Li S, Miguel E, Jombart T, Lessler J, Cauchemez S, Cori A (2019) Improved inference of time-varying reproduction numbers during infectious disease outbreaks. Epidemics 29:100356

Wallinga J, Teunis P (2004) Different epidemic curves for severe acute respiratory syndrome reveal similar impacts of control measures. Am J Epidemiol 160:509-516

Wei Y, Wang Y, Di Q, Choirat C, Wang Y, Koutrakis P, Zanobetti A, Dominici F, Schwartz JD (2019) Short term exposure to fine particulate matter and hospital admission risks and costs in the Medicare population: time stratified, case crossover study. BMJ 367:16258

Wu F, Zhao S, Yu B, Chen YM, Wang W, Song ZG, Hu Y, Tao ZW, Tian JH, Pei YY, Yuan ML, Zhang YL, Dai FH, Liu Y, Wang QM, Zheng JJ, Xu L, Holmes EC, Zhang YZ (2020) A new coronavirus associated with human respiratory disease in China. Nature 579: 265-269

Xie J, Teng J, Fan Y, Xie R, Shen A (2019) The short-term effects of air pollutants on hospitalizations for respiratory disease in Hefei, China. Int J Biometeorol 63:315-326

Xu Z, Shi L, Wang Y, Zhang J, Huang L, Zhang C, Liu S, Zhao P, Liu H, Zhu L, Tai Y, Bai C, Gao T, Song J, Xia P, Dong J, Zhao J, Wang FS (2020) Pathological findings of COVID-19 associated with acute respiratory distress syndrome. Lancet Respir Med 8:420-422

Yao Y, Pan J, Wang W, Liu Z, Kan H, Qiu Y, Meng X, Wang W (2020) Association of particulate matter pollution and case fatality rate of COVID-19 in 49 Chinese cities. Sci Total Environ 741:140396

Publisher's note Springer Nature remains neutral with regard to jurisdictional claims in published maps and institutional affiliations. 